\title{
Optimization of management control costs in the context of transaction expenses (in terms of an educational organization)
}

\author{
M.V. Chuvashlova ${ }^{1}, M . N$. Pavlenkov $^{2}$, and O.F. Ermishina ${ }^{1, *}$ \\ ${ }^{1}$ Ulyanovsk State University, Lva Tolstogo street, 42, 432970 Ulyanovsk, Russian Federation \\ ${ }^{2}$ Lobachevsky National Research Nizhny Novgorod State University, Gagarin Ave., 23, 603950 \\ Nizhny Novgorod, Russian Federation
}

\begin{abstract}
The article examines the importance of management control for optimizing the transaction expenses in an educational organization. The author highlighted the opinions of the economists from various theoretical positions. Examples of changes in the optimal control costs, the occurrence of losses from the organization of ineffective control nave been considered, possible ways of solving the problems that have arisen have been given. The extensive material has been structured, which made it possible to highlight the relevance of the study of transaction expenses. According to the authors, the minimum amount of control costs is determined at the point of equality of explicit and implicit transaction costs, that is, the losses of the organization and the costs of executing contracts. At the same time, the optimal amount of control costs will be in the area of relevance of the marginal costs of control and the marginal benefits from the implementation of control measures. Deviations from this zone in any direction are undesirable for the organization.
\end{abstract}

\section{Introduction}

An integrated interdisciplinary approach to the management of organizations from the standpoint of the theory of management control examines the processes and mechanisms used by organizations in order to influence the behavior of subjects within the organization and, through this, facilitate the implementation of various kinds of tasks that arise everywhere in the organization.

The results of the study of the economic literature indicate that this subject area was justified from various theoretical positions, including the concepts and principles from such disciplines as systems theory, institutional economics, organization theory and psychology, which helps us to better understand control as a phenomenon and as a process. Nevertheless, the question of the use of certain tools or methods of control corresponding to emerging management situations, as well as the justification of their effectiveness, including for an educational organization, remains open for scientific discussion.

\footnotetext{
* Corresponding author: ermof19@mail.ru
} 
As a rule, in educational organizations the internal control system is carried out by a specially created department. The specialists in this structure have a certain level of qualification to know all the "pitfalls" for effective management. However, at the moment, the internal control system and optimization of costs for it requires further study.

\section{Materials and methods}

Organizational control systems serve several purposes. Jensen and Mecklin (1992) [1] argue that a control system provides incentives by measuring and evaluating performance, and by using reward and punishment instruments. The authors agree that along with the system that delimits the rights to make the decisions, the control system of the organization compensates for the absence of an "invisible hand" coordinating the activities in the market. Speckle (2004) [2] takes a similar broad view of control systems for governance. He reduces the main objectives of management control systems to knowledge gathering, coordination, and incentives through rewards and punishments.

Various combinations of control instruments are used to achieve these goals. [3]. For example, the formation of knowledge that remains within the organization and is available for use in decision-making can be accomplished by delegating tasks and responsibilities to those who have this knowledge. In addition, financial rewards provide incentives and can induce purposeful behavior.

The authors believe that the effectiveness of control tools in terms of managing the transformation costs of any organization lies in the plane of management accounting, from budgeting to analysis of variances, and is not the subject of this article.

But the effectiveness of the control tools in terms of managing transaction expenses is the subject of scientific discussion of modern management. However, not all authors clearly share the difference in approaches to control in the theory of transformation and transaction expenses. So, G. Demsetz criticizes the theory of the firm solely from the standpoint of transaction expenses, sees its weakness in the absence of accounting for production costs, which leads to neglect of differences between firms if they are not related to the control function [4].

Let us turn again to the theory of transaction costs, which has already become mainstream in the history of research on management control [5]. Despite the fact that in most of the previous works, the main attention was focused on the problems of control in specific situations, or control tools, the benefits of using the theory of transaction expenses are far from being limited to a narrow focus - in fact, this theory allows you to lay a reliable basis for building a more general and meaningful theoretical basis for the subsequent study of the structures of management control.

The theory of transaction expenses allows you to take the first steps towards substantiating such an important concept as optimal control costs. Calculation of the optimal amount of expenses is necessary for making many management decisions in any organization, including an educational one. First of all, calculating the optimal amount of control costs helps to plan these costs, include them in the organization's budget. Secondly, knowing the actual value and structure of such costs, their best option, it is possible to develop measures to reduce control costs, thereby creating new motivational incentives for the controllers themselves. And thirdly, the calculation of the optimal amount of control costs will be the first and most important step towards the study of efficiency [6].

The optimal control costs we consider as the best state of the management control system "in relation to its goals under the given external and internal conditions" [7]. This interpretation of the concept of economic optimum involves the study of management processes and factors that determine this optimum. What influences the optimal amount of control costs? To do this, it is necessary to understand the structure of control costs and 
identify the factors that affect them. Control costs or control expenses are broadly a part of transaction expenses. They are associated with the process of concluding and implementing the internal contracts of the organization. May include both explicit and implicit costs. These include: costs of maintaining a controlling service, costs of ensuring control in other departments and services of the organization, costs of monitoring the implementation of internal contracts, costs of minimizing opportunistic behavior within the organization and other types of the expenses, including losses as a result of improper performance contracts [8], which will be discussed separately.

The relationship between the magnitude of explicit transaction expenses and the magnitude of control costs is obvious. Control costs are an integral part of transaction expenses. With an increase in transaction expenses, there is a corresponding increase in control costs. Let's reflect this proportional dependence on graph 1.

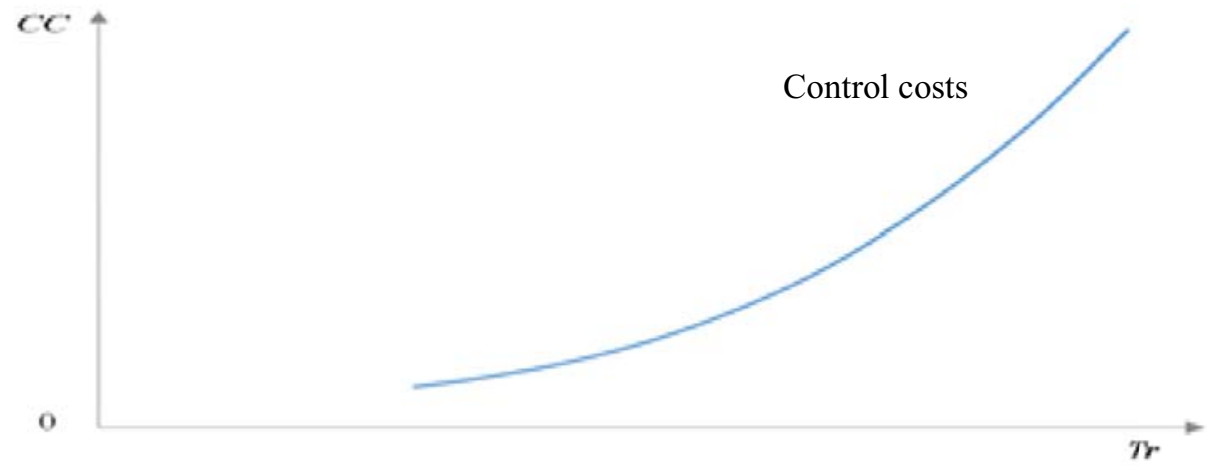

Fig. 1. Schedule of control expenses. Compiled by the authors.

The question arises, is the graph describing the dependence of control costs on the value of transaction costs linear? Most likely not, since control costs do not directly depend on the level of business activity or opportunistic behavior of controllers, or on any other quantifiable factors. Undoubtedly, only their stable proportional dependence to the value of explicit transaction expenses. If there is an increase in transaction costs caused by the conclusion of new contracts, entry into new markets, production and sale of new types of products, all this will undoubtedly require new control costs, which will be reflected in an increase in the corresponding costs. Let us assume that point $\operatorname{Tr} 1$ in the presented graph corresponds to the current level of transaction expenses and the corresponding level of expenses for control $\mathrm{CC}$. In the case of an increase in transaction expenses (movement to the right along the $0 \mathrm{Tr}$ axis), other things being equal, there will be an increase in control costs (movement up along the $0 \mathrm{CC}$ axis).

Consider what other factors besides the magnitude of transaction expenses affect the total costs of control. This is, of course, an applicable control model that may or may not be effective in an organization. A more suitable control model will allow maintaining the same amount of control costs with an increase in transaction expenses, the shift of the curve "control costs" to the right (Figure 2.).

Other factors that influence the value of control costs in addition to transaction expenses can be: opportunistic behavior (shift of the curve to the left), developed corporate culture (shift of the curve to the right), and other factors. A shift in the control cost curve to the right entails a decrease at the same value of transaction expenses.

In addition to explicit transaction expenses, which include the costs of executing internal and external contracts, the amount of control costs is also affected by implicit transaction expenses, which include various kinds of losses. 


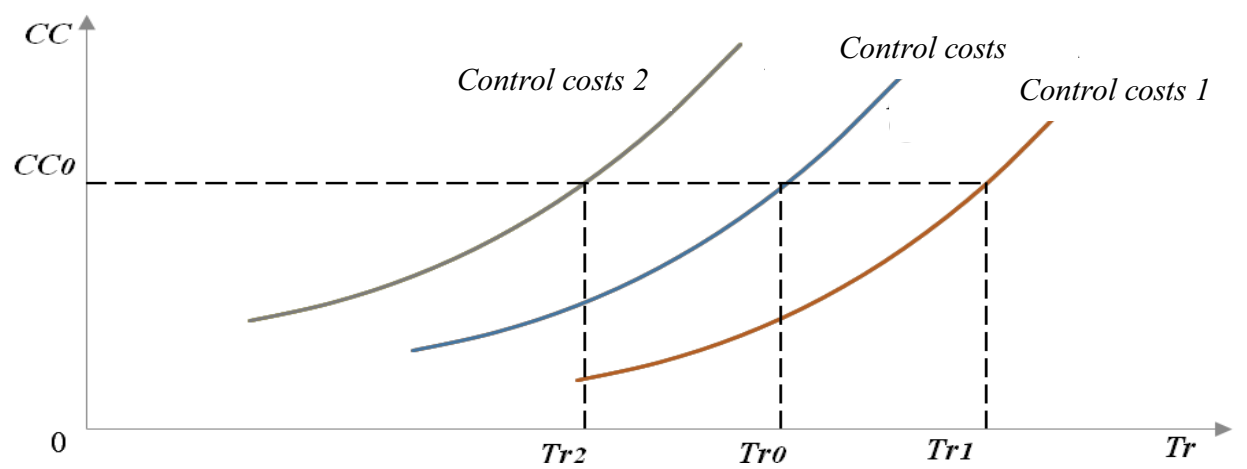

Fig. 2. A shift in the control cost curve under the influence of various factors. Compiled by the authors.

These include losses from shortages, theft and damage to property, shortages from depreciation of inventories, losses from overdue debts, losses from non-fulfillment of the terms of contracts, and others. A certain relationship can also be traced between the amount of losses and the amount of control costs. The less an organization spends on control, the higher its potential losses. Let's reflect this dependence on graph 3.

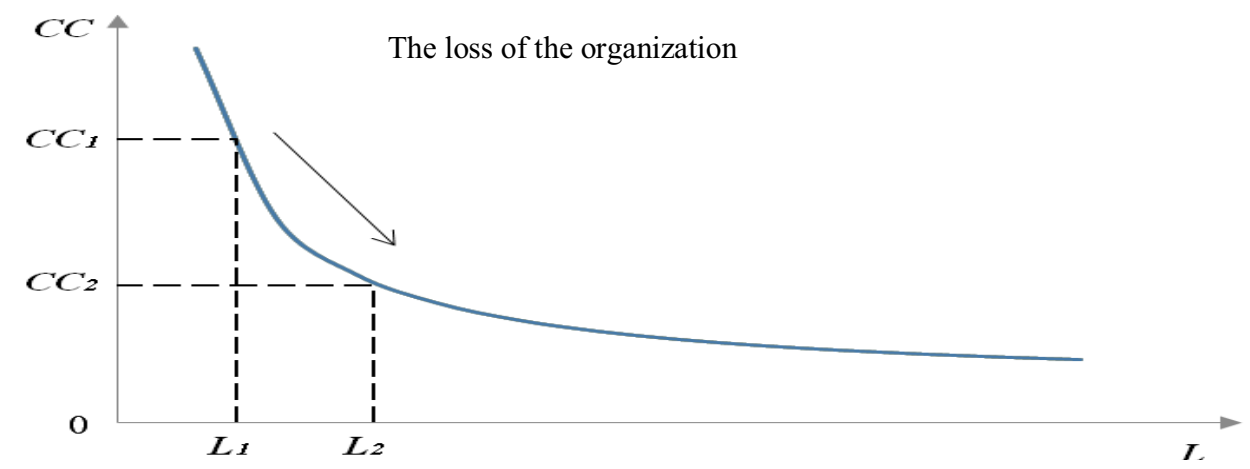

Fig. 3. Graph of the organization's losses from ineffective control. Compiled by the authors.

As can be seen from graph 3, if the control costs are insufficient (CC1), then various kinds of losses to the organization will be great, since proper control over compliance with internal and external contracts is not ensured. As the number of control activities increases, control costs begin to increase, which reduces the implicit costs, namely, losses and expenses of the organization. Thus, the dependence is inversely proportional.

Consider what factors, in addition to control costs, can affect the amount of losses to the organization? These are primarily factors that ensure the effectiveness of the control system. A shift in the "loss of organization" curve to the right indicates ineffective control instruments, since at the same value of transaction costs, losses to an organization will be higher. 


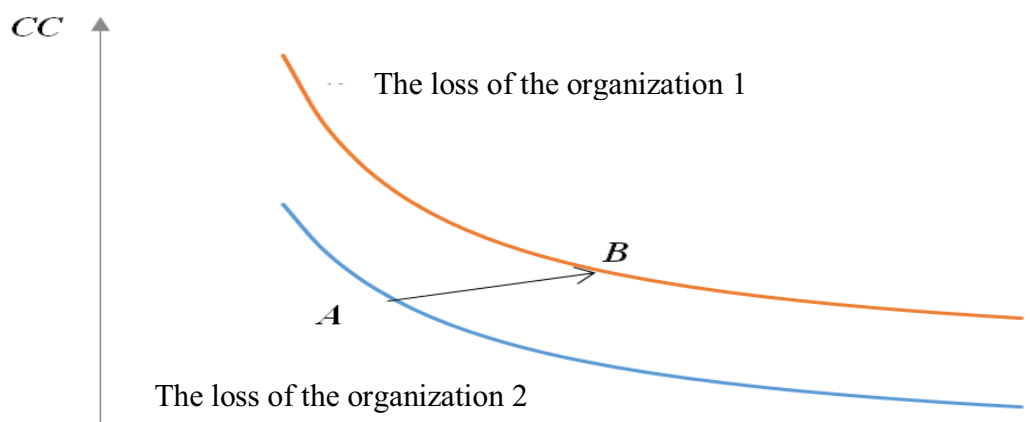

I.

Fig. 4. A shift in the organization's loss schedule from ineffective control under the influence of various factors. Compiled by the authors.

Thus, having substantiated the main factors that ensure the determination of the optimal amount of control costs, as part of the amount of losses and the amount of transaction expenses, we can conclude that the optimal amount of control costs can be in the zone of optimum losses and the transaction expenses themselves. Let's show the result of the study in graph 5.

$\mathrm{Z}$ curve, which summarizes the total expenses of the organization for the provision of control measures and compensation for damages and losses, has a U-shape. As can be seen from the graph, in order for the total control costs to be minimal (Cmin), the costs of ensuring the management control system must be comparable to the damages and losses from ineffective control.

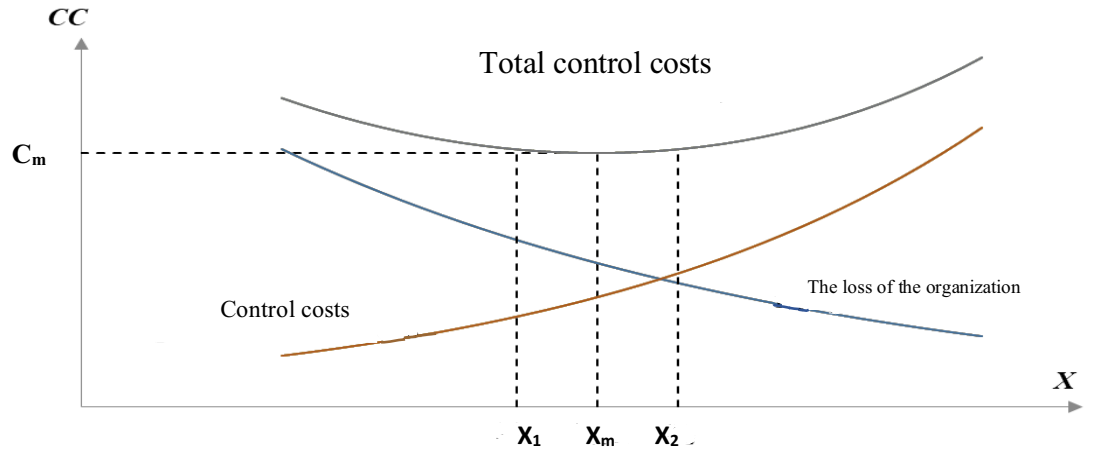

Fig.5. Schedule of total control costs. Compiled by the authors.

This will happen in an area where the marginal cost of control will not exceed the marginal benefit of the control. Thus, it is possible to identify a certain area within which the total costs are close to their absolute minimum. $\left[\mathbf{X}_{1} ; \mathbf{X}_{2}\right]$ The minimum amount of control costs is possible at the point of equality of explicit and implicit transaction costs as well, that is, the losses of the organization and the costs of executing contracts. But this condition is not at all obligatory for every organization. At the same time, the optimal amount of control costs will be in the area of relevance of the marginal costs of control and the marginal benefits from the implementation of control measures. Deviations from this zone in any direction are undesirable. 


\section{Results and discussion}

Let us calculate the optimal amount of control costs using the example of FSBI HE Ulyanovsk State University using actual data. For this purpose, we will take for the analysis the reporting data for 2010-2019. (Table 1).

Table 1. Reporting data of FSBI HE "Ulyanovsk State University" for 2010-2019.

\begin{tabular}{|c|l|l|l|l|l|l|l|}
\hline Years & $\begin{array}{l}\text { Losses } \\
\text { from } \\
\text { shortages, } \\
\text { theft and } \\
\text { damage to } \\
\text { property, } \\
\text { thousand } \\
\text { rubles }\end{array}$ & $\begin{array}{l}\text { Fines } \\
\text { and } \\
\text { penalties, } \\
\text { thousand } \\
\text { rubles }\end{array}$ & $\begin{array}{l}\text { The amount } \\
\text { of losses } \\
\text { from the } \\
\text { execution of } \\
\text { internal and } \\
\text { external } \\
\text { contracts, } \\
\text { thousand } \\
\text { rubles }\end{array}$ & $\begin{array}{l}\text { Expenses } \\
\text { for the } \\
\text { execution } \\
\text { of internal } \\
\text { contracts } \\
\text { adminis- } \\
\text { trative } \\
\text { expenses), } \\
\text { thousand } \\
\text { rubles }\end{array}$ & $\begin{array}{l}\text { Expenses for } \\
\text { the execution } \\
\text { of external } \\
\text { contracts } \\
\text { commercial } \\
\text { expenses), } \\
\text { thousand } \\
\text { rubles }\end{array}$ & $\begin{array}{l}\text { The amount } \\
\text { of expenses } \\
\text { for the } \\
\text { execution of } \\
\text { internal and } \\
\text { external } \\
\text { contracts, } \\
\text { thousand } \\
\text { rubles }\end{array}$ & $\begin{array}{l}\text { Estimated } \\
\text { value of } \\
\text { control } \\
\text { costs, } \\
\text { thousand } \\
\text { rubles }\end{array}$ \\
\hline 2010 & 0 & 13 & 13 & 4399 & 11870 & 16269 & 44 \\
\hline 2011 & 0 & 24 & 24 & 5622 & 16838 & 22460 & 56 \\
\hline 2012 & 487 & 765 & 1252 & 15185 & 14928 & 30113 & 152 \\
\hline 2013 & 601 & 147 & 748 & 17695 & 16086 & 33781 & 177 \\
\hline 2014 & 0 & 390 & 390 & 20380 & 18285 & 38665 & 204 \\
\hline 2015 & 10602 & 0 & 10602 & 23319 & 15923 & 39242 & 233 \\
\hline 2016 & 8389 & 0 & 8389 & 25511 & 11997 & 37508 & 255 \\
\hline 2017 & 8771 & 208 & 8979 & 26636 & 7785 & 34421 & 266 \\
\hline 2018 & 8439 & 1002 & 9441 & 35488 & 15395 & 50883 & 355 \\
\hline 2019 & 235 & 1061 & 1296 & 33584 & 27168 & 60752 & 336 \\
\hline
\end{tabular}

To plot the control costs, we will take the amount of costs for the execution of external contracts and the amount of costs for the execution of internal contracts as the amount of transaction expenses. For the explicit costs of internal contracts, we will take the general business expenses of the organization or, as they are called in the statement of financial results, the administrative expenses. For the costs of external contracts, we will take the commercial expenses of the organization, since it is the commercial expenses that include the explicit costs of securing the external contracts. As an estimated value of control costs, we will take $2 \%$ (this value was formed based on the results of a survey of employees of internal control services of educational organizations) of transaction expenses according to a questionnaire survey of departments and services of FSBI HE Ulyanovsk State University, the data will be reflected in Figure 6.

The relationship between transaction expenses and control costs is significant, with reliability above $99 \%$. The trend is stable at the $76 \%$ level, it can be written as a dependence

$$
C C=29,577^{*} \exp \left(4,867 E-05^{*} T r\right)
$$

To plot the organization's losses from ineffective control, we also take the data on the estimated value of control costs. 


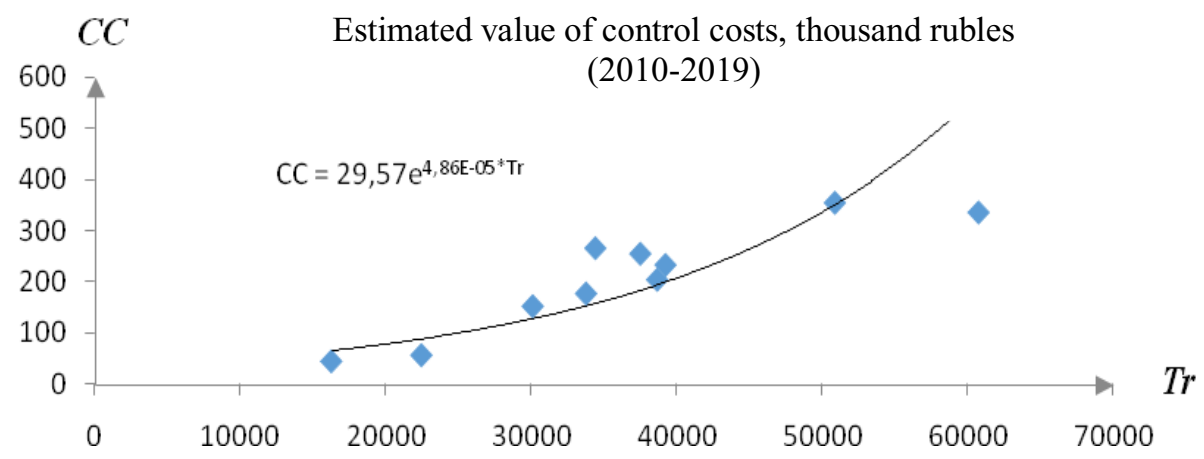

Fig. 6. Schedule of total control costs by divisions of FSBI HE Ulyanovsk State University. Compiled by the authors.

The amount of losses (implicit transaction expenses) will be calculated as the sum of losses of the organization, fines, penalties paid, thereby including in the calculations both losses from the execution of internal contracts, and losses from the execution of external contracts. These calculations can be rather arbitrary, but these data in our case are the only available information from official reporting, applicable in the study of transaction expenses. Primary analysis of the data characterizing the magnitude of losses showed that they are unstable, which is confirmed by their visual observation (Fig. 7).

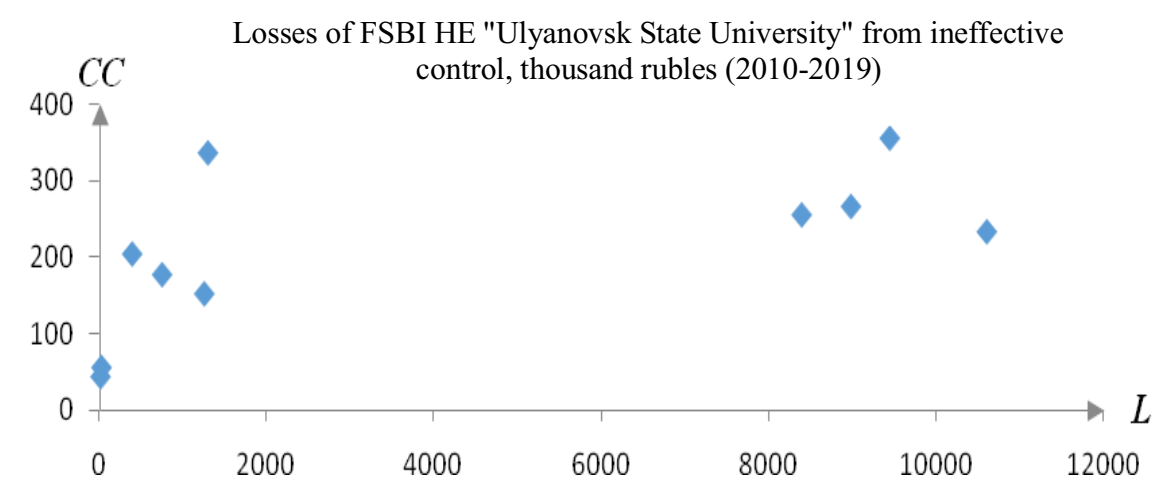

Fig. 7. Losses of FSBI HE "Ulyanovsk State University" from ineffective control. Compiled by the authors.

At the next stage of the analysis, the data for the period 2010-2014 were excluded, since for this period the statistical data are small in their absolute value, which can give rise to an error in their assessment, in turn, the data of 2018 should be discarded as uncharacteristic for FSBI HE "Ulyanovsk State University". The indicators of 2018 should not be considered in general statistics, since this period is characterized by an atypical situation with a significant share of losses with a sufficiently high value of control costs. This is due to the fact that during the formation of financial statements in 2018, it was decided to carry out one-time operations for the impairment of non-current assets (equipment for scientific, technical and educational and laboratory facilities). 
This was situationally reflected in the net loss and expenses at the end of the reporting period. Let us construct a graph of losses (Figure 8) of FSBI HE Ulyanovsk State University from ineffective control.

The relationship between the amount of losses to the organization and control costs is significant with a reliability of $98 \%$. The trend is stable at the level of $95 \%$, it can be written as a dependence

$$
C C=395,955^{*} \exp \left(-3,703 E-05^{*} L\right)
$$

Now it is possible to draw up a graph of the total control costs according to the data of FSBI HE "Ulyanovsk State University" (Figure 9). In this case, the point $\left(\boldsymbol{C}_{\boldsymbol{l}}, \boldsymbol{X}_{\boldsymbol{I}}\right)=(239,9$; $25770,7)$ is the point of minimum total control costs. This means that for a given educational organization the optimal value of control costs is 239.9 thousand rubles, which will ensure the minimization of the organization's losses and its explicit transaction expenses.

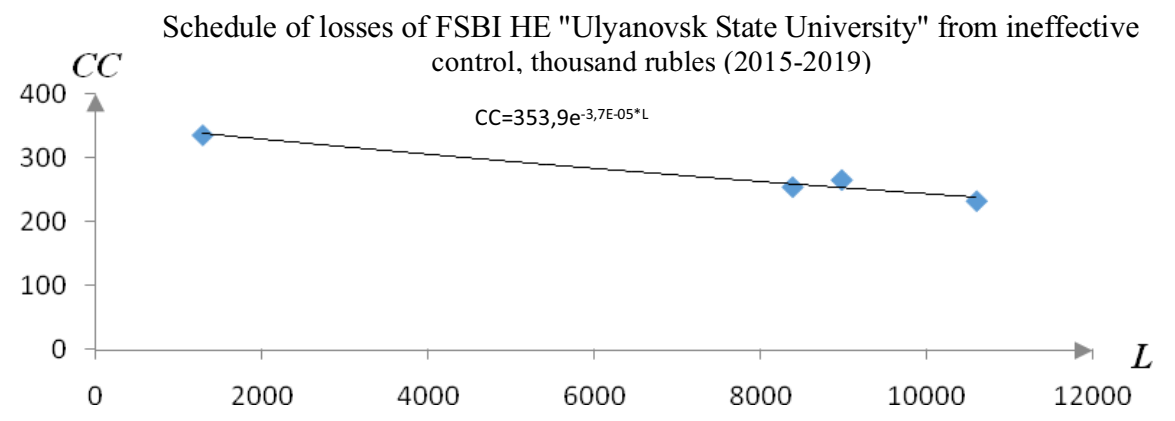

Fig. 8. Schedule of losses of FSBI HE "Ulyanovsk State University" from ineffective control. Compiled by the authors.

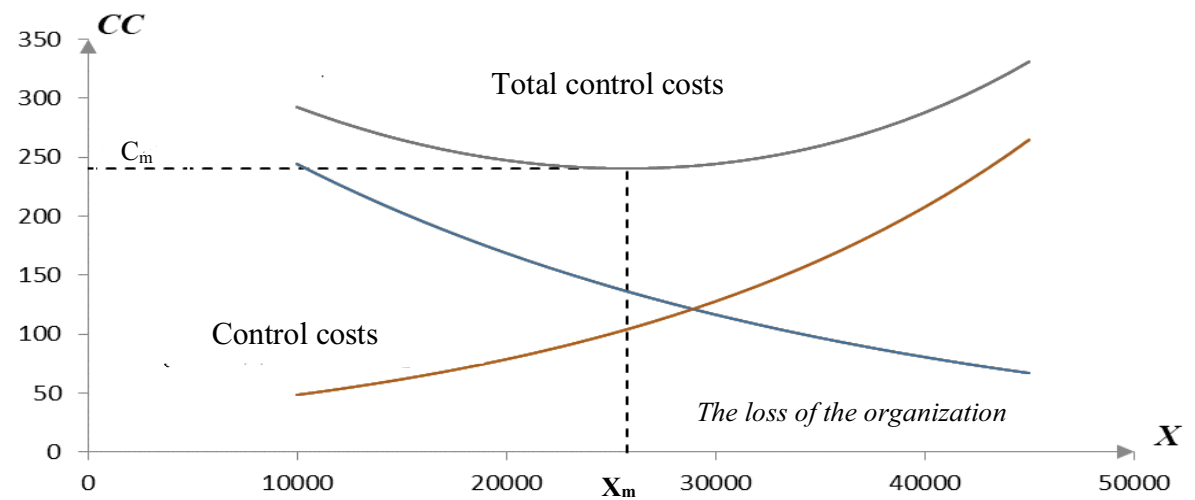

Fig. 8. Schedule of total control costs of FSBI HE Ulyanovsk State University. Compiled by the authors.

\section{Conclusion}

This study can be expanded to include a third dimension and a third parameter that affects the effectiveness of control - the degree to which the organization has achieved its goals. It is possible to assess the influence of this factor and substantiate what amount of control 
costs will be optimal, taking into account the implementation of KPIs, by resorting to expert judgment. As a result of a survey of employees of the internal control service and heads of departments of the FSBI HE "Ulyanovsk State University", it was revealed at what amount of expenses for control the achievement of KPI is maximum. It can be assumed that there are areas of insufficient control, the achievement of KPI is minimal, optimal control $\mathrm{KPI}$ is the most achievable and excessive control, KPI is again decreasing.

Traditionally, transaction expenses include the cost of completing business transactions, including the monetary estimate of the time spent finding a business partner, negotiating, concluding a contract, and ensuring the appropriate performance of the contract. The main idea of using the theory of transaction expenses in solving management control problems is, in our opinion, that the achievement of an organization's goals depends on the participation and personal contribution of a large number of people and their interaction, and the structures of management control act as a means for solving coordination problems. adaptation, motivation and control of performance by concluding an agreement while monitoring the personal contribution of each participant.

\section{References}

1. M.C. Jensen, and W.H. Meckling, Contract economics, 251 (1992).

2. R.F. Speklé, Configurations of control: a transaction cost approach (working paper) (2004).

3. K.A. Merchant, Sloan Management Review, 43 (1982)

4. 4.H. Demsetz, Quarterly Journal of Economics, 1, 243 (2000)

5. Spekle, 2001, Colbert and Spicer, 1995; Van der Meer-Kooistra and Vosselman, 2000; Spicer and Ballew, 1983; Swieringa and Waterhouse, 1982; Tiessen and Water-house, 1983.

6. M. Chuvashlova, European Research Studies Journal, 3, 675 (2018)

7. Economic dictionary, http://abc.informbureau.com/

8. R. Coase, R. Firm, market and law (2007) 